\title{
Health-Related Quality of Life Outcomes Following Elective Open or Endovascular AAA Repair: A Randomized Controlled Trial
}

\author{
Patricia E.M. Lottman, MSc ${ }^{1}$; Robert J.F. Laheij, MSc, PhD ${ }^{1,2}$; \\ Philip W.M. Cuypers, MD, PhD²; Mart Bender, MD²; and Jacob Buth, MD, PhD² \\ ${ }^{1}$ Department of Medical Technology Assessment, University Medical Center St. \\ Radboud, Nijmegen, The Netherlands. 'Department of Vascular Surgery, \\ Catherina Hospital, Eindhoven, The Netherlands.
}

\begin{abstract}
$\longrightarrow \longrightarrow$
Purpose: To assess health-related quality of life outcomes after endovascular versus open abdominal aortic aneurysm repair.

Methods: Participants were randomly assigned to receive either endovascular or open abdominal aortic aneurysm (AAA) surgery according to a rate of 3 endovascular patients to 1 with open repair. Data on patient characteristics, operative aspects, and procedural and device-related complications were compiled at a single center. Health-related quality of life was assessed before treatment and 1 and 3 months following operation using the Medical Outcomes Study Short-Form 36-item Health Survey (SF-36) and the EuroOol questionnaire.

Results: Between 1996 and 1999, 57 patients (54 men; mean age 69 years, range 52-82) underwent endovascular and 19 patients (16 men; mean age 68 years, range 52-81) underwent open AAA repairs. Preoperatively, comparable scores were recorded in both treatment groups. One month after operation, patients of both groups scored significantly lower on the SF-36 domains of Role Limitations due to physical problems and Pain compared to preoperative scores. Three months after operation, both groups had scores in all domains comparable to preoperative levels of functioning. There was a significant benefit for the endovascular group 1 month after operation in the SF-36 domains of Physical Functioning, Role Limitations due to physical problems, Vitality, and Pain; their score on the EuroQol Usual Activities item was also significantly better. After 3 months, there were no longer differences between groups.
\end{abstract}

Conclusions: Short-term health-related quality of life benefits were found after endovascular repair compared with standard open surgery.

J Endovasc Ther 2004;11:323-329

Key words: abdominal aortic aneurysm, endovascular repair, surgery, comparative study, quality of life, health survey questionnaire

Endovascular stent-graft repair of abdominal aortic aneurysms (AAA) has several advantages and disadvantages over classical surgical procedures. Open surgery has proven to be durable but is still associated with high op- erative morbidity and prolonged recovery. The results from several studies have shown that operative mortality and morbidity after open surgery varies between $3 \%$ and $8 \%$ and $10 \%$ to $23 \%$, respectively. ${ }^{1-3}$ On the other

\footnotetext{
Address for correspondence and reprints: Robert J.F. Laheij, Department of Medical Technology Assessment, University Medical Center Nijmegen, P.O. Box 9101, 6500 HB Nijmegen, The Netherlands. Fax: 31-24-3610383; E-mail: R.Laheij@mdl.umcn.nl
} 
hand, endovascular repair is a new technique in which long-term results are still lacking. Operative mortality after endovascular repair seems lower in comparison with open surgery. ${ }^{2,3}$ However, a major disadvantage of stent-graft repair seems to be the high incidence of late complications, which mandate lifelong surveillance ${ }^{4-6}$ and cause a high rate of secondary interventions, including conversion to open surgery. Moreover, rupture of the aneurysm sporadically occurs after endovascular repair. ${ }^{7}$ However, the endotechnique is evolving, and greater operator experience produces better procedural results and fewer postoperative complications. ${ }^{8}$

It is relatively unknown if this type of intervention has any impact on the patient's perception of relative health status. So far, only a few studies have investigated differences in quality of life outcomes after aneurysm repair. ${ }^{9-11}$ However, these studies might be biased because of nonrandomization. Especially when subjective outcomes are involved, a randomized clinical trial provides the best insurance that the observed results are due to the intervention under scrutiny. The aim of this study was to compare short-term healthrelated quality of life aspects in a randomized controlled trial of elective endovascular versus open AAA repair.

\section{METHODS}

\section{Study Design}

The trial was conducted between September 1996 and October 1999. Consecutive patients were considered for enrollment from 2 hospitals. Patients with AAAs in need of elective treatment were eligible; exclusion criteria were adverse aneurysm morphology for endovascular repair, contrast allergy, unfitness for open surgery, or patient refusal to participate in the study. The ethics committees of our hospitals approved the protocol. All the participants gave written informed consent before taking part in the study.

Eligible patients were consecutively numbered according to a list generated by a central randomization computer system and allocated into one of two different groups.
Randomization used a 3:1 ratio for endovascular repair versus open surgery because equal groups would have reduced the experience of the team involved with the endovascular technique.

Baseline information was recorded, which included demographic data, clinical characteristics, and vascular morphology. Operative data included the type of endograft, operative details, and the occurrence of complications. Health-related quality of life was assessed before operation and at 1 and 3 months afterwards using the Medical Outcomes Study Short Form 36-item Health Survey (SF-36) ${ }^{12}$ and the EuroQol ${ }^{13}$ questionnaire. The SF-36 is scored on 8 domains: Physical Functioning, Social Functioning, Role Limitations-physical, Role Limitations-emotional, Mental Health, Vitality, Pain, and General Health. The EuroOol classification consists of 5 items to describe health status: Mobility, Self-care, Usual Activities, Pain/Discomfort, and Anxiety/Depression. Additionally, patient self-evaluation of health status was assessed with a visual analogue scale ranging from 0 (worst imaginable health state) to 100 (best imaginable health state). Questionnaires were filled out irrespective of doctor visits.

\section{Patient Population}

During the period of enrollment, 89 patients (70 men; mean age 68 years, range 52-82) were considered for randomization between endovascular repair and open surgery. Thirteen patients were not randomized because of poor medical condition or refusal to participate, which left 57 patients (54 men; mean age 69 years, range 52-82) assigned to endovascular repair and 19 (16 men; mean age 68 years, range $52-81$ ) to open surgery. Patient characteristics were similar in both groups at baseline (Table 1). One of the patients randomized to endovascular repair suffered aneurysm rupture and had to undergo emergency open surgery; he was included in the endovascular repair group anyway.

\section{Statistical Analysis}

The results are presented as the mean \pm 
TABLE 1

Baseline Characteristics, Operative Data, and Clinical Outcome

\begin{tabular}{|c|c|c|}
\hline & $\begin{array}{l}\text { Open Surgery } \\
\qquad(n=19)\end{array}$ & $\begin{array}{l}\text { Endovascular } \\
\qquad(n=57)\end{array}$ \\
\hline Mean age, y (range) & $68(52-81)$ & $69(52-82)$ \\
\hline Men & $16(84 \%)$ & $54(95 \%)$ \\
\hline Mean maximum aneurysm diameter, mm (range) & $52(40-61)$ & $56(52-84)$ \\
\hline ASA $\|/\|^{*}$ & $15(79 \%) / 4(21 \%)$ & $34(60 \%) / 23(40 \%)$ \\
\hline \multicolumn{3}{|l|}{ Graft configuration } \\
\hline Bifurcated & 3 & 57 \\
\hline Straight & 16 & - \\
\hline Median operative time, $\min$ & $180(120-270)$ & $180(65-320)$ \\
\hline Median ICU stay, h & $21(16-360)$ & $19(8-90)$ \\
\hline Median length of hospital stay, $d$ & $11(8-50)$ & $5(2-21)$ \\
\hline Endoleaks at completion arteriography & - & $12(21 \%)$ \\
\hline Mortality at 30 days & $1(5 \%)$ & $1(2 \%)$ \\
\hline
\end{tabular}

standard deviation, as proportions with percentages, or as means with $95 \%$ confidence intervals $(\mathrm{Cl})$. Analysis was performed with nonparametric tests; paired data were compared with the Wilcoxon signed rank test and unpaired data with the Wilcoxon rank sum test. The chi-square test was used to analyze proportional differences in contingency tables. $\mathrm{P}<0.05$ was regarded as statistically significant.

\section{RESULTS}

Operative time and length of stay in the intensive care unit (ICU) (Table 1) were comparable between the groups. The length of hospitalization after endovascular and open surgery were 5 days $(95 \% \mathrm{Cl} 2$ to 21$)$ and 11 days $(95 \% \mathrm{Cl} 8$ to 50$)$, respectively $(p<0.05)$. Eighteen (95\%) of the 19 patients in the open surgery group completed the SF-36 and EuroQol before operation; at the 1 and 3month intervals, 17 (89\%) patients completed the forms. In the 57-patient endovascular group, 54 (95\%) patients completed the questionnaires preoperatively, while $52(91 \%)$ patients filled out the forms at 1 and 3 months after operation. On the EuroQol questionnaire, however, only 155 of the 158 responses from the endovascular group could be analyzed (questionnaires with missing answers were excluded, as the EuroQol does not provide a system to integrate missing answers).

The raw data from the SF-36 were transformed into standard scores from 0 to 100 , with higher scores indicating better quality of life. ${ }^{14}$ The results of the SF-36 and the EuroQol in the 2 treatment groups are represented in Tables 2 and 3 respectively. There were no significant differences in preoperative scores between patients with open or endovascular surgery. One month after operation, patients of both groups scored significantly lower than preoperatively on the SF-36 domains of Role Limitations due to physical problems (open surgery $p<0.01$; endovascular $p<0.05)$ and Pain $(p<0.01)$. In addition, the scores of the open surgery group were significantly lower than baseline for the SF-36 domains of Physical Functioning $(p<0.05)$ and Vitality $(p<0.01)$; in the EuroQol form, the Usual Activities score was also significantly lower $(p<0.01)$. The endovascular group had a significantly lower level of functioning than before treatment for the SF-36 domain of Social Functioning $(p<0.05)$. Three months after operation, patients of both 
TABLE 2

Scores From the SF-36 Before Operation and at 1 and 3 Months

\begin{tabular}{|c|c|c|c|c|c|c|}
\hline & \multicolumn{3}{|c|}{ Open Surgery } & \multicolumn{3}{|c|}{ Endovascular } \\
\hline & $\begin{array}{l}\text { Preop } \\
(n=18)\end{array}$ & $\begin{array}{l}1 \text { Month } \\
(n=17)\end{array}$ & $\begin{array}{l}3 \text { Months } \\
(n=17)\end{array}$ & $\begin{array}{l}\text { Preop } \\
(n=54)\end{array}$ & $\begin{array}{l}1 \text { Month } \\
(n=52)\end{array}$ & $\begin{array}{l}3 \text { Months } \\
(\mathrm{n}=52)\end{array}$ \\
\hline Physical Functioning & $68 \pm 26$ & $44 \pm 27 \dagger$ & $77 \pm 23$ & $68 \pm 24$ & $61 \pm 24 \ddagger$ & $70 \pm 26$ \\
\hline $\begin{array}{l}\text { Social Functioning } \\
\text { Role Limitations }\end{array}$ & $78 \pm 20$ & $56 \pm 33$ & $83 \pm 16$ & $83 \pm 24$ & $71 \pm 27 \dagger$ & $86 \pm 16$ \\
\hline Physical & $52 \pm 43$ & $13 \pm 25^{*}$ & $57 \pm 45$ & $62 \pm 45$ & $44 \pm 42 \dagger \ddagger$ & $64 \pm 46$ \\
\hline Emotional & $65 \pm 45$ & $40 \pm 46$ & $69 \pm 43$ & $64 \pm 48$ & $56 \pm 46$ & $79 \pm 37$ \\
\hline Mental Health & $71 \pm 26$ & $63 \pm 25$ & $77 \pm 24$ & $69 \pm 27$ & $74 \pm 23$ & $73 \pm 23$ \\
\hline Vitality & $68 \pm 28$ & $39 \pm 25^{*}$ & $64 \pm 26$ & $63 \pm 26$ & $55 \pm 24 \ddagger$ & $63 \pm 26$ \\
\hline Pain & $83 \pm 30$ & $45 \pm 32 *$ & $83 \pm 17$ & $84 \pm 25$ & $70 \pm 28 * \ddagger$ & $88 \pm 17$ \\
\hline General Health Perceptions & $53 \pm 19$ & $54 \pm 24$ & $43 \pm 23$ & $52 \pm 30$ & $47 \pm 26$ & $63 \pm 30$ \\
\hline
\end{tabular}

Scores are presented as mean \pm standard deviation.

* $p<0.01$ for within-group comparisons relative to preop.

$\dagger p<0.05$ for within-group comparisons relative to preop.

$\neq p<0.05$ for between-group comparisons.

TABLE 3

Scores From the EuroQol Before Operation and at 1 and 3 Months

\begin{tabular}{|c|c|c|c|c|c|c|}
\hline & \multicolumn{3}{|c|}{ Open Surgery } & \multicolumn{3}{|c|}{ Endovascular } \\
\hline & $\begin{array}{l}\text { Preop } \\
(n=18)\end{array}$ & $\begin{array}{l}1 \text { Month } \\
(n=17)\end{array}$ & $\begin{array}{c}3 \text { Months } \\
(n=17)\end{array}$ & $\begin{array}{c}\text { Preop } \\
(n=53)\end{array}$ & $\begin{array}{l}1 \text { Month } \\
(n=52)\end{array}$ & $\begin{array}{c}3 \text { Months } \\
(n=50)\end{array}$ \\
\hline \multicolumn{7}{|l|}{ Mobility } \\
\hline No problems & 50 & 29 & 53 & 53 & 42 & 52 \\
\hline Problems & 50 & 65 & 47 & 47 & 54 & 46 \\
\hline Confined to bed & 0 & 6 & 0 & 0 & 4 & 2 \\
\hline \multicolumn{7}{|l|}{ Self-care } \\
\hline No problems & 100 & 82 & 88 & 83 & 85 & 86 \\
\hline Some problems & 0 & 12 & 6 & 17 & 13 & 12 \\
\hline Unable to & 0 & 6 & 6 & 0 & 2 & 2 \\
\hline \multicolumn{7}{|l|}{ Usual Activities } \\
\hline No problems & 44 & $12 *$ & 65 & 57 & $46 \dagger$ & 62 \\
\hline Some problems & 56 & 53 & 29 & 36 & 42 & 34 \\
\hline Unable to & 0 & 35 & 6 & 7 & 12 & 4 \\
\hline \multicolumn{7}{|l|}{ Pain/Discomfort } \\
\hline None & 55 & 29 & 59 & 62 & 58 & 60 \\
\hline Some & 39 & 65 & 41 & 32 & 36 & 40 \\
\hline Extreme & 6 & 6 & 0 & 6 & 6 & 0 \\
\hline \multicolumn{7}{|l|}{ Anxiety/Depression } \\
\hline None & 50 & 65 & 82 & 62 & 73 & 80 \\
\hline Some & 22 & 29 & 12 & 30 & 23 & 18 \\
\hline Extreme & 18 & 6 & 6 & 8 & 4 & 2 \\
\hline Health self-evaluation $\ddagger$ & $61 \pm 17$ & $61 \pm 16$ & $61 \pm 17$ & $67 \pm 18$ & $68 \pm 14$ & $67 \pm 18$ \\
\hline
\end{tabular}

* $p<0.01$ for within-group comparisons relative to preoperatively.

$\dagger p<0.05$ for between-group comparisons.

¥ Scores are presented as mean \pm standard deviation based on 100 . 


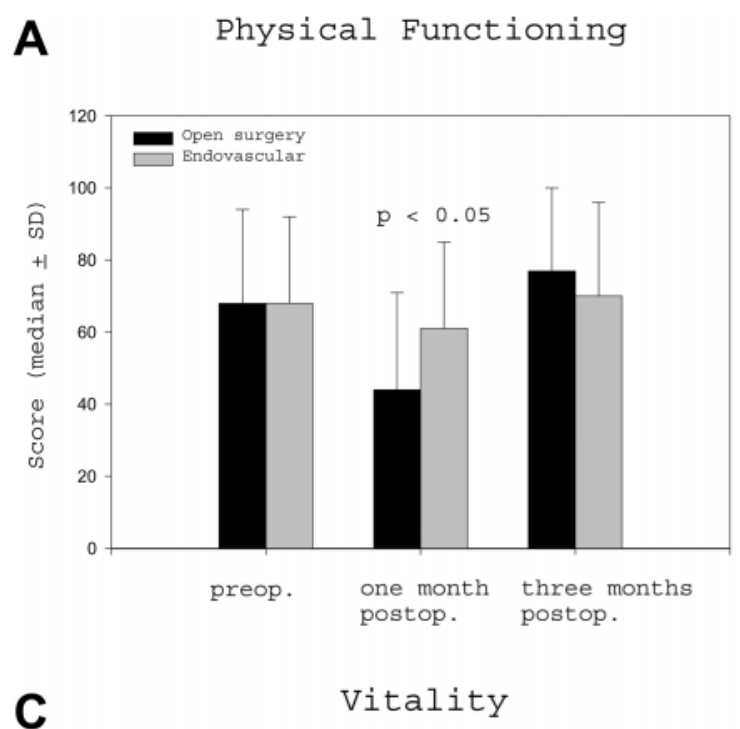

B Role Limitations (physical)
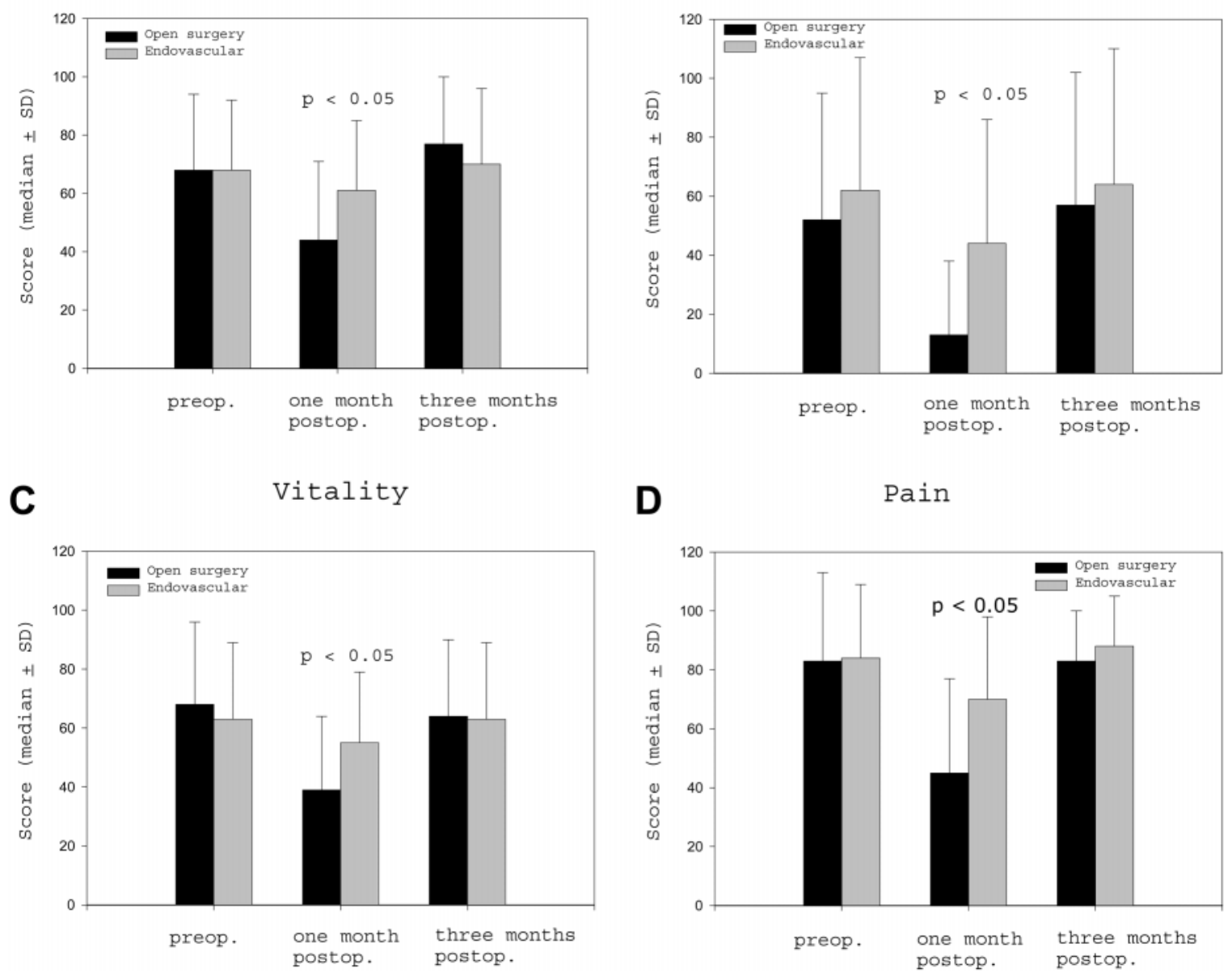

Figure Health-related status assessed by the SF-36 questionnaire before the operation (preop) and at 1 and 3 months postop. Represented domains are (A) Physical Functioning, (B) Physical Role Limitations, (C) Vitality, and (D) Pain. These domains demonstrate significantly lower scores in patients with open aneurysm surgery at 1 month postoperatively.

groups returned to their preoperative functional levels across all domains.

The postoperative scores were compared between the open and endovascular groups (Figure). One month after operation, the open surgery patients scored significantly lower on the SF-36 domains of Physical Functioning $(p<0.05)$, Role Limitations due to physical problems $(p<0.05)$, Vitality $(p<0.05)$, and Pain $(p<0.05)$. Similarly, the Usual Activities $(p<0.05)$ item in the EuroQol questionnaire at 1 month was lower in patients after open surgery. At 3 months of follow-up, there were no longer differences between the treatment groups.

\section{DISCUSSION}

The benefit for the endovascular group in short-term (up to 1 month) health-related quality of life outcomes confirms the less invasive nature of this type of intervention. Patients undergoing endovascular surgery achieve better physical functioning and are in less pain 1 month after operation, which may result in an improvement in their vitality and ability to conduct usual activities.

Unlike earlier cohort-based, nonrandomized studies, ${ }^{9-11}$ ours was a randomized controlled trial to evaluate the impact of elective open versus endovascular AAA surgery 
on health-related quality of life. The shortterm results from our study are consistent with the findings of Aquino et al., ${ }^{11}$ although they reported a more pronounced deterioration in quality of life (using the SF-36) for their open surgery group 1 week after operation and a more delayed recovery (up to 8 weeks). Conversely, our results are quite different from those presented by Malina et al., ${ }^{9}$ who showed similar health-related quality of life using the Nottingham Health Profile (NHP) in both groups at 5 days after operation. A possible explanation for this contrast may be attributed to the use of different health assessment questionnaires. The SF-36 and NHP approach different domains from a somewhat different perspective. For example, the SF-36 domains of Physical Functioning, Social Functioning, and Role Limitations (in which the open surgery and endovascular surgery group did differ) are not addressed by the NHP. Furthermore, the SF-36 domain of Pain refers more generally to the amount of bodily pain and resulting interference with normal work, whereas the NHP domain of pain relates to walking or standing.

The present study demonstrated similar health-related quality of life outcomes at 3 months after operation for both groups, which is consistent with previous reports that showed no differences between groups in health-related quality of life at 3 to 6 months follow-up. ${ }^{9-11}$

One limitation to our study is that the data were collected 4 years prior to this analysis. Moreover, the data encompass, to some extent, the learning curve for the endovascular procedures, reflected in the 19-hour ICU stay and the 5-day hospitalization for endovascular patients. These admission times were significantly longer than would currently be encountered; in the most recent 100 patients treated at one of our institutions, for example, only 25 patients were admitted to the ICU and remained there for a median 3.6 hours. Duration of hospital stay in the same cohort had dropped to a median of 4.4 days (range 2-25). However, it would be difficult to see shorter admission times influencing better outcomes in quality of life parameters in the stent-graft cohort after 1 month.

In conclusion, this randomized controlled trial suggests that the only benefit in healthrelated quality of life for endovascular patients is in the short term (up to 1 month) for the domains of Physical Functioning, Physical Problems, Pain, Vitality and Usual Activities. No advantages in the patient's perceived health-related quality of life at 3 months after treatment emerged from this study.

\section{REFERENCES}

1. Blankensteijn JD. Mortality and morbidity rates after conventional abdominal aortic aneurysm repair. Semin Interv Cardiol. 2000;5:7-13.

2. Treiman GS, Lawrence PF, Edwards WH, et al. An assessment of the current applicability of the EVT endovascular graft for treatment of patients with an infrarenal abdominal aortic aneurysm. J Vasc Surg. 1999;30:68-75.

3. May J, White GH, Waugh R, et al. Improved survival after endoluminal repair with secondgeneration prostheses compared with open repair in the treatment of abdominal aortic aneurysms: a 5-year concurrent comparison using life table method. J Vasc Surg. 2001;33: S21-26.

4. May J, White G, Yu W, et al. Concurrent comparison of endoluminal versus open repair in the treatment of abdominal aortic aneurysms: analysis of 303 patients by life table method. $J$ Vasc Surg. 1998;27:213-221.

5. Schurink GWH, Aarts NJM, van Bockel JH. Endoleak after stent-graft treatment of abdominal aortic aneurysm: a meta analysis of clinical studies. Br J Surg. 1999;86:581-587.

6. May J, White GH, Yu W, et al. Endoluminal repair of abdominal aortic aneurysms: strengths and weaknesses of various prostheses observed in a 4.5-year experience. J Endovasc Surg. 1997;4:147-151.

7. Teufelsbauer H, Prusa AM, Prager M, et al. Endovascular treatment of a multimorbid patient with late AAA rupture after stent-graft placement: 1-year follow-up. J Endovasc Ther. 2002; 9:895-901.

8. Laheij RJ, van Marrewijk CJ, Buth J, et al. The influence of team experience on outcomes of endovascular stenting of abdominal aortic aneurysms. Eur J Vasc Endovasc Surg. 2002;24: 128-133.

9. Malina M, Nilsson M, Brunkwall J, et al. Quality of life before and after endovascular and open repair of asymptomatic AAAs: a prospective study. J Endovasc Ther. 2000;7:372-379.

10. Lloyd AJ, Boyle J, Bell P, et al. Comparison of 
cognitive function and quality of life after endovascular or conventional aortic aneurysm repair. Br J Surg. 2000;87:443-447.

11. Aquino RV, Jones MA, Zullo TG, et al. Quality of life assessment in patients undergoing endovascular or conventional AAA repair. J Endovasc Ther. 2001;8:521-528.

12. Ware JE, Sherbourne CD. The MOS 36-item short form health survey (SF-36). I. Conceptual framework and item selection. Med Care. 1992; 30:473-483.

13. Essink-Bot ML, Stouthard ME, Bonsel GJ. Generalizability of valuations on health states collected with the EuroQolc questionnaire. Health Econ. 1993;2:237-246.

14. Ware JE, Snow KK, Kosinski MA. SF-36 Health Survey Manual and Interpretation Guide. Boston, MA: New England Medical Centre; 1993. 